REFERENCES

EDMONDS, E. M., \& EVANS, S. H. Schema learning without a prototype. Psychonomic Science, 1966,5, 247-248. EDMONDS,E., \& MUELLER, M. The role of schemata in perceptual learning. Psychonomic Science, 1967a, 8, 239-240.

EDMONDS, E., \& MUELLER, M. Schema discrimination without external reinforcement. Perceptual \& Motor Skills. $1967 \mathrm{~b}, 24,436-438$.

EDMONDS, E., MUELLER, M., \& EVANS, S. Effects of knowledge of results on mixed schema discrimination. Psychonomic Science, 1966, 6, 377-378.

EDWARDS, $W$, The theory of decision making. Psychological Bulletin, 1954, 51 . $380-417$.

EDWAR DS , W. , LINDMAN, H., \& PHILLIPS, L. D. Emerging technologies for making decisions. In New directions in psychology, II. New York: Holt, Rinehart, \& Winston, 1965. Pp. 261-325.
EVANS, S. H. A model for perceptual category formation. Unpublished doctoral dissertation. Texas Christian University, 1964.

FORGUS, R. H. Perception. New York: McGraw-Hill, 1966

GUILFORD, J. P. The nature of human intelligence. New York: MeGraw-Hill, 1967.

KOGAN, N., \& WALLACH, M. A. New directions in psychology, III. New York: Holt, Rinehart, \& Winston, 1967.

MYERS, I. L., \& KATZ, L. Range of payoffs and feedback in risk taking. Psychological Reports, 1962, 10. 483-486.

O'NEIL, W. M. Basic issues in perceptual theory. Psychological Review, 1958, 65, 348-361.

RAPAPORT, A. Two-person game theory Ann Arbor: University of Michigan Press, 1966.

von FIEANDT, K. The world of perception. Homewood, Ill: Dorsey Press, 1966.

\title{
Number as a stimulus in a card-sorting task
}

\author{
ROBERT M. ADAMS* \\ University of Tennessee, Knoxville, Tenn. 37916
}

Human Ss performed a card-sorting task and were asked afterward to report the number of responses they had made in a sequence. Ability to give the correct number was found to vary as a function of the size of the number and as a function of the dissimilarity of the sequence-ending card. Ss who did not count the sequence length overestimated the length. The results are discussed in terms of the concept of number as a stimulus in psychophysical investigation.

Psychophysical studies have been carried out to establish the values of many types of stimuli which govern responses of the nature of, "Yes, I see it." The present study sought information about the stimulus "number." While there is a literature on estimates of numbers of things presented simultaneously (e.g., Kaufman, Lord, Reese, \& Volkmann 1949), this study investigated estimates of numbers of things presented sequentially, without instructing Ss to look for the number. The procedure was essentially that of the "no instructions to learn" group in incidental learning studies (e.g., McLaughlin, 1965) but with a task S would not fail to learn if instructed to do so.

\section{SUBJECTS}

The Ss were 90 male and 30 female students in the introductory psychology course at the University of Tennessee who were required to participate in one experiment per quarter. Ss were assigned to groups without regard to sex by their order of signing a list.

\section{APPARATUS}

The stimulus materials for the study were the backs of ordinary playing

*Now at Fort Hays Kansas State College. Hays, Kans. 67601 . cards, including a great variety of animals, birds, outdoor scenes, houses, geometric patterns, and flowers. Duplication of cards seldom exceeded four of the same picture. No two identical cards were adjacent, and all pictures were presented rightside up.

\section{PROCEDURE}

Upon arrival, $\mathbf{S}$ was taken into a $2 \times 2^{1 / 2} \mathrm{~m}$ room and seated at a $1 \times 1 \mathrm{~m}$ table. Temperature in the room was approximately $75^{\circ} \mathrm{F}$, and an overhead fan both ventilated the room and masked outside noise. The E seated himself across from $S$ with notebook and pencil. In front of $S$ was a row of stacks of playing cards, faces down, with each stack containing about 60 cards.

The $\mathbf{S}$ was then given the following instructions: "I'd like you to pick up each deck of cards, and looking at the backs, sort them one at a time into two stacks according to whether the picture contains a ship or a boat [the target card] or does not, like this. [The $E$ then picks up a deck of cards and places two of them in a stack, one at a time, and then a third beside them.] So when you are finished you will have two stacks of cards, one with ships and boats, and one with everything else." The $E$ then answered any questions, and $\mathrm{S}$ began sorting the cards. Questions usually served to confirm that the task was indeed as simple as it appeared.

The Ss were assigned randomly to one of nine groups. Seven groups were designated with the numbers $2-8$, according to the placement of the target cards throughout the decks. For Group 2, the target card was every second card, for Group 3, every third card, and so on, through to every eighth card. There were $10 \mathrm{Ss}$ in each of Groups 2, 3, 7, and 8 and 20 Ss in each of Groups 4, 5, and 6. Two groups of 10 Ss were tested on a variation of Group 6 and designated Group 6-S and Group 6-F. Each S was tested for only one session, lasting approximately $10 \mathrm{~min}$.

For each $S$, there were 80 target cards picturing boats with sails. For each $S$, the total number of cards to be sorted was equal to 80 (the number of target cards) times the group number $(2-8)$. At the end of the last deck, there was a run of cards without a target card. Ss in Group 4, for example, were required to sort 4 times 80 cards, plus an additional five nontarget cards at the end, for a total of 325 cards. The run at the end (equal to the group number plus one) was intended to yield a nonverbal indication of whether or not $S$ had counted placement of target cards. Would the $S$ pause at the card that normally would be the target card?

At the end of the task, $S$ was asked the following: (1) "Do you have any comments or observations?" If $S$ did not reply with a statement about the placement of the cards, he was asked: (2) "Did you notice any regularity in the placement of the boats?" Again, if $S$ did not specify the placement, he was asked: (3) "How many cards do you think were between the boats?" If $S$ indicated that he had counted the number between the boats, he was asked in what deck he first noticed the systematic placement.

For Group 6-S, the five cards between target cards were grouped according to the subject of the pictures. The target card might follow five dogs, five Indians, five geometric figures, five flowers, etc. The second added group, 6-F, was given random cards in the interval between target cards, but the target cards were placed in the deck face up. The face-up cards were random in regard to card value (number). All other details of the procedure were identical to Group 6 . RESULTS

Sixty-three Ss indicated they had counted the number of cards between target cards, and the percentage of each group counting was found to be a function of this number. All but one $S$, who had counted target card 
Table 1

Percent of $\mathrm{Ss}$ in Each Group Who Counted the Interval Between Target Cards (Group number is the number of cards between target cards)

\begin{tabular}{lccccccc}
\hline Group & Two & Three & Four & Five & Six & Seven & Eight \\
Percent Counting & 100 & 90 & 50 & 50 & 25 & 30 & 30 \\
\hline
\end{tabular}

placement, reported the interval length in answer to, or prior to, Question 2 ("regularity"); generally, this was done in answer to Question 1 ("comments or observations"). Several Ss commented correctly on the placement while sorting the cards. All those Ss who were asked Question 2 before reporting the interval length were in groups in which a high roportion of Ss counted (Groups 2-4 and $6-F$ ). It appeared that the failure to report the interval length in answer to Question 1 was due to the fact that it was too obvious for comment. The questions asked at the end, then, discriminated well between counters and noncounters.

Table 1 shows the percent of Ss in each group who counted the intervals (i.e., number of cards from one target card to the next). The percentages for Groups 4, 5, and 6 are based on 20 Ss each; all other percentages are for 10 Ss. The distance between target cards was a strong factor in determining whether or not Ss would count the interval $\left(x^{2}=13.4\right.$, df $\left.=6, p<.05\right)$. No $\mathrm{S}$ failed to count when target cards were alternated with nontarget cards. When target cards were farther apart than every fifth card (Groups 6, 7, and 8 ), no more than $30 \%$ of Ss counted. There was a regular and consistent decline in the proportion of counters as a function of the increasing interval between target cards.

The percent of $\mathrm{Ss}$ counting also increased with the dissimilarity of the target card to the other cards in the sequence. The percent of counters for Group 6, reported above, was 25 . Arranging the cards so that the five cards between target cards were homogeneous (five pictures of the same thing) yielded a figure of $50 \%$ counting (Group 6-S). Changing the target card to a face-up card while leaving all other cards face down (Group 6-F) yielded $80 \%$ counters.

Estimates of the number of cards between target cards is shown in Table 2 as a function of actual number for all Ss who failed to count in Groups 4-8. The deviation of the estimate from the true interval is positive for every group. In short, Ss who could not state the exact interval length showed a marked tendency to overestimate the interval. Of a total of $48 \mathrm{Ss}^{1}$ only 4 underestimated the interval and only 1 made an accurate guess. The probability that the likelihood of an overestimate by these
Ss is the same as the likelihood of an underestimate is less than .001 .

Pauses in the final run of cards did not prove sufficiently clear to be used by itself as an adequate indicator of whether or not $S$ had counted. This observation, together with the appearance of a sudden increase in rate of response, did usually indicate that $S$ had counted, however. It appeared that $S$ discovered the regularity and then began to sort the cards more rapidly. The card in the last run which normally would have been a target card of ten elicited a look of mild puzzlement.

Groups $5-8$ contained a total of 16 females in a total of 60 Ss. Half of them counted as opposed to $35 \%$ overall. The group-by-group proportion of female counters was very similar to the overall proportion, indicating that a difference in counting due to sex was not likely $\left(x^{2}=2.65\right.$, df $=3, \mathrm{p}>.30$ )

\section{DISCUSSION}

The conclusions drawn are based on the opinion that this experiment was in fact, a psychophysical experiment investigating some variables affecting "number" as a stimulus. A stimulus can be considered a property or event in the environment that can be shown to control behavior (cf. Verplanck, 1957). In this case, the behavior under control was the response to the questions at the end of sorting. In effect, $E$ was presenting a series of numbers of units with no explicit instructions and asking $S$ if he "saw the number."

The number stimuli, 2-8, were presented 80 times to $\mathrm{S}$. For the sequences of random cards ending with the picture of a boat, the threshold can be considered the series of lengths 4 or 5 , the point at which number was a stimulus for $50 \%$ of the Ss. (Contrary to most types of stimuli, of course, likelihood of detection varies inversely with magnitude.) The discriminability of the number stimulus can be altered by making the beginning and end of the sequence more discriminable.

Table 2

Noncounters' Median Estimates of Number of Cards Between Target Cards

\begin{tabular}{lccccc}
\hline $\begin{array}{l}\text { Correct } \\
\text { Number }\end{array}$ & 3 & 4 & 5 & 6 & 7 \\
$\begin{array}{l}\text { Median } \\
\text { Estimate }\end{array}$ & 4.5 & 5.5 & 6.5 & 8.5 & 9
\end{tabular}

In the card-sorting experiment, Ss appeared either to be counting or guessing. Subitizing, as defined by the inventors of the term (Kaufman et al, 1949), did not take place in this sequential, rather than simultaneous, presentation. Perhaps judgments of sequential stimuli (or responses to them) differ qualitatively from judgments of stimuli presented simultaneously, but there is no readily appareis justification for this conclusion.

Judgments of numbers of dots simultaneously presented do differ quantitatively from judgments of numbers of cards. Accuracy of judgments of sequence length of cards breaks down at a total sequence length of 4 , as opposed to a dot total of 6-7. Also, when errors in dot estimation begin to appear, there is a slight tendency to overestimate between 7 and 10 , only if instructions stress accuracy of responding rather than speed (Kaufman et al, 1949). Sequential estimations were almost invariably too high in this range, and the percent of error was much higher. Other studies also report underestimation of large numbers (e.g. Bevan, Maier, \& Helson, 1963; Bevan \& Turner, 1963; Taves, 1941).

Interpretation of the present study as a memory experiment may be suggested; however, it would be difficult, if not impossible, to determine if noncounting Ss put the number "into storage" and forgot it. It would seem more parsimonious to say that S did not learn or "see" the number than to say that the number was lost due to decay or interference. Eighty presentations of the number, and the short interval between the final presentation and report of the number, would seem to preclude such an interpretation.

\section{REFERENCES}

BEVAN, W., MAIER, R., \& HELSON, H The influence of context on the estimation of number. American Journal of Psychology, 1963, 76, 464-469.

BEVAN, W., \& TURNER, E. Assimilation and contrast in the estimation of number. Journal of Experimental Psychology. $1964,67,458-462$

KAUFMAN, E. L., LORD, M. W., REESE, T. W., \& VOLKMANN, J. The discrimination of visual number. American Journal of Psychology, 1949. $62,498-525$

McLAUGHLIN, B. "Intentional" and "incidental" learning in human subjects: The role of instructions to learn and motivation. Psychological Bulletin, 1965. $63,359-376$.

TAVES, E. H. Two mechanisms for the perception of visual numerousness. Archives of Psychology, 1941, 37, 1-47.

VERPLANCK, W. S. A glossary of some terms used in the objective science of behavior. Psychological Review, 1957, 64 (Monograph Supplement). NOTE

1. The $E$ failed to record the estimate of one $S$. 